\title{
Un diagnóstico de Grecia
}

\section{Chee-Heong Quah ${ }^{*}$}

\begin{abstract}
Resumen
Este trabajo explora el nivel de competitividad internacional de Grecia e investiga el grado de correspondencia entre las condiciones en este país y las que dictan la teoría de las zonas monetarias óptimas (ZMO). Dado que Grecia comparte ahora la misma moneda con Alemania, el país central de facto en la eurozona, los hallazgos indican que los problemas en el país griego podrían haberse exacerbado por la pérdida de competitividad mercantil en relación con Alemania o la ausencia de convergencia con la economía central en las diferentes áreas asociadas a las ZMO (integración económica, nivel del ingreso, etc.).
\end{abstract}

Palabras clave: Unión Económica Monetaria (UEM), deuda, Grecia, ciclo económico, unión monetaria, integración, euro.

Clasificación JEL: E62, F31, F32, F41, F42, O53.

\section{INTRODUCCIÓN}

Las economías avanzadas que enfrentan problemas fiscales hoy en día comparten las mismas raíces con respecto a su debilidad subyacente (véase, por ejemplo, Buiter y Rahbari, 2010). En primer lugar se tienen las políticas procíclicas que adoptaron las autoridades fiscales y monetarias durante los años del auge posterior a la burbuja tecnológica de 2000; en segundo, los costos directos asociados con la turbulencia financiera mundial de 2007-2008, incluidos los costos del rescate y, en tercero, la consiguiente recesión mundial que minó los ingresos e incrementó los gastos públicos. En cuanto a Grecia, su gobierno incluso disimuló su posición presupuestaria real.

En el caso de la crisis griega, las agencias calificadoras y las autoridades de la eurozona también deben cargar con parte de la responsabilidad. En efecto, la incapacidad que mostraron las agencias calificadoras para reconocer el riesgo

Manuscrito recibido en marzo de 2012; aceptado en octubre de 2013.

* Facultad de Empresa y Contabilidad, University of Malaya, Kuala Lumpur, Malasia <quahch@um. edu.my>. El autor agradece los valiosos comentarios de tres dictaminadores anónimos de la revista. 
inherente en las enormes sumas de bonos que emitió el gobierno griego, se tradujo en bajos niveles de tasas de interés de largo plazo. Esto contribuyó a alimentar una burbuja especulativa que, al estallar, ni el Banco Central Europeo (BCE), ni los gobiernos de la eurozona pudieron ponerse de acuerdo respecto a la utilidad de la degradada deuda griega como garantía de préstamo para este país.

El 10 de mayo de 2010, el BCE inició su Programa para los Mercados de Valores (SMP, por sus siglas en inglés) para aplicar políticas monetarias mediante la compra de bonos del gobierno. Este programa fue una desviación del principio que mantenía la eurozona en cuanto a no rescatar gobiernos por la vía de políticas monetarias. A pesar de ello, hubo desacuerdos respecto al smp en el seno del Consejo de Gobierno del BCE. En el BCE había básicamente dos puntos de vista opuestos (Panico y Purificato, 2013): el primero respaldaba al SMP, quería atemperar fuerzas especulativas mediante la compra de grandes cantidades de títulos públicos; mientras que el segundo objetaba dicha medida debido a que creía que la crisis la ocasionaban debilidades estructurales, como la falta de competitividad y el libertinaje fiscal. Este segundo punto de vista afirmaba también que el SMP sólo liberaría a los países deudores del rigor de la disciplina del mercado y que distribuiría el riesgo de la deuda hacia todos los contribuyentes de la eurozona. Al mismo tiempo, los medios esparcieron temores infundados respecto a las operaciones del BCE, lo que significaba un reto para que las autoridades pusieran en práctica soluciones definitivas.

Además de esto, el origen de los errores de Grecia no es ajeno a su déficit relativamente alto en programas básicos de seguridad social, como pensiones y salud; pero la crisis y las medidas tomadas para contrarrestarla profundizaron la escasez de recursos que el país necesitaba para proporcionar la protección social necesaria para amortiguar las consecuencias de la misma (Matsaganis, 2011).

Otros autores, como Milios y Sotiropoulos (2010), relacionan los problemas de Grecia con desequilibrios estructurales dentro de la eurozona. Altas tasas de crecimiento en las economías "periféricas" a la par de una rápida reducción en los costos del endeudamiento interno, en el marco de una política monetaria única, dieron como resultado la entrada significativa de ahorro externo que contribuyó a financiar los déficit en la cuenta corriente. Este financiamiento externo alivió las presiones sobre los consumidores, que de otra forma se hubieran visto obligados a reducir su consumo.

Todavía hay una tercera perspectiva. De Grauwe y Ji (2012) sugieren que la crisis fue producto de la incapacidad de las autoridades europeas para enfrentar 
los movimientos de capitales especulativos (generados por los conflictos con el BCE), los temores infundados que esparcieron los medios respecto al funcionamiento de la Unión Monetaria y el creciente riesgo para los contribuyentes de los países acreedores con relación a aquellas políticas que eran distintas a las basadas en la austeridad.

Por otra parte, en un trabajo reciente, Krugman (2012) sostiene que si bien los desequilibrios entre los estados deficitarios y superavitarios en los Estados Unidos pueden de alguna manera equilibrarse por las convergencias en áreas de la zona de moneda óptima (ZMO) provocadas por las transferencias fiscales (Kenen, 1969) y la migración de la fuerza de trabajo (Mundell, 1961), los desequilibrios entre el centro y la periferia en la eurozona, lejos de tener estas características, son una causa básica de la crisis en dicha zona. Previamente, en un estudio relativo a las ZMO, Barbosa y Alves (2011) encontraron que diferencias en el crecimiento de los costos unitarios de trabajo, en el comercio y en el crecimiento del producto eran causas significativas de competitividad divergente entre algunos estados de la Unión Económica Monetaria (UEM). Más recientemente, Quah $(2013 a ; 2014)$ detecta una creciente fragmentación en la sincronización del ciclo económico dentro de la eurozona, después de la crisis financiera y económica mundial.

En vista de lo anterior, este trabajo analiza los niveles de competitividad internacional de Grecia, concentrándose en el tipo de cambio real y en el grado de correspondencia entre las condiciones que dicta la teoría de las ZMO (distintas a las ya mencionadas en la literatura) con la situación real de este país. En esencia, considerando que Grecia comparte actualmente la misma moneda con Alemania, el país central de facto en la eurozona, las dificultades en Grecia pudieron verse exacerbadas por la pérdida de competitividad comercial en relación con Alemania o por la falta de convergencia con dicho país en las áreas económicas correspondientes a la ZMO. De ahí que resulte natural utilizar a Alemania como el país de referencia para el análisis.

Para ello, la muestra de datos utilizados comprende en general el periodo de 1992 a 2009/2011, considerando los posibles efectos del Tratado de Maastricht de 1992, el nacimiento del euro en 1999, la “euroización” de Grecia en 2001 y la crisis global de 2007-2008. Dado que el periodo examinado comprende el periodo de implementación real del euro en Grecia, uno puede verificar si ha habido una mayor convergencia con Alemania después de la "euroización". 
Después de esta introducción el trabajo está organizado como sigue: la segunda sección analiza algunos indicadores de desempeño económico de la economía griega, como antecedentes del tema en discusión; la sección tercera examina el nivel de competitividad internacional de Grecia, concentrándose en los movimientos de los tipos de cambio reales; la cuarta sección introduce los criterios de las ZMO y se evalúa el grado de conformidad de Grecia con respecto a dichos criterios. En ambas secciones, la tres y la cuatro, el desempeño económico griego es evaluado con relación al de Portugal e Irlanda, países que están, al igual que Grecia, sujetos a los programas de ajuste acordados con las autoridades europeas. La quinta sección aborda el examen de los hallazgos y sus posibles implicaciones y, finalmente, en el último apartado se presentan las conclusiones.

\section{Desempeño de Grecia vis-À-vis con Alemania}

Recurriendo a algunos indicadores macroeconómicos de uso generalizado, esta sección compara el desempeño de Grecia con el de Alemania. Los temas que examinamos son: el equilibrio presupuestario, el endeudamiento público, la balanza en cuenta corriente, la inversión extranjera directa (IED), los flujos de capital privado y el desempleo.

La gráfica 1 muestra la posición del presupuesto del gobierno central como porcentaje del producto interno bruto (PIB) a lo largo del periodo 1992-2012 para Grecia y Alemania. Evidentemente, los déficit presupuestarios en Grecia siempre han sido mayores en comparación con los de Alemania. A pesar de la mejoría en los años cercanos a 1999, muy probablemente debido a la conformidad con el Tratado de Maastricht, los déficit en la economía griega comenzaron a deteriorarse y divergir de los de Alemania a partir de finales de la década de 1990. También se observa en la trayectoria griega una caída en 2004 que coincide con la Olimpiada en Grecia y un profundo bache en 2007-2009, durante la crisis económica global.

No obstante, el desempeño del balance fiscal de las autoridades griegas en términos de niveles (sin compararlo con el de Alemania), fue en gran medida razonable hasta 2005, antes de la caída de las finanzas públicas tras la reforma del Pacto de Estabilidad y Crecimiento de 2005 y el fracaso de las políticas de austeridad para conseguir una reducción del déficit público previsto por el programa de ajuste de la Comisión Europea, el BCE y el FMI (Arestis y Pelagidis, 2010; Papadimitriou, Nikiforos y Zezza, 2013). Pese a ello, en 2010 hubo un 


\section{GRÁFICA 1}

Balanza presupuestal de Grecia y Alemania, 1992-2012

(como porcentaje del PIB)

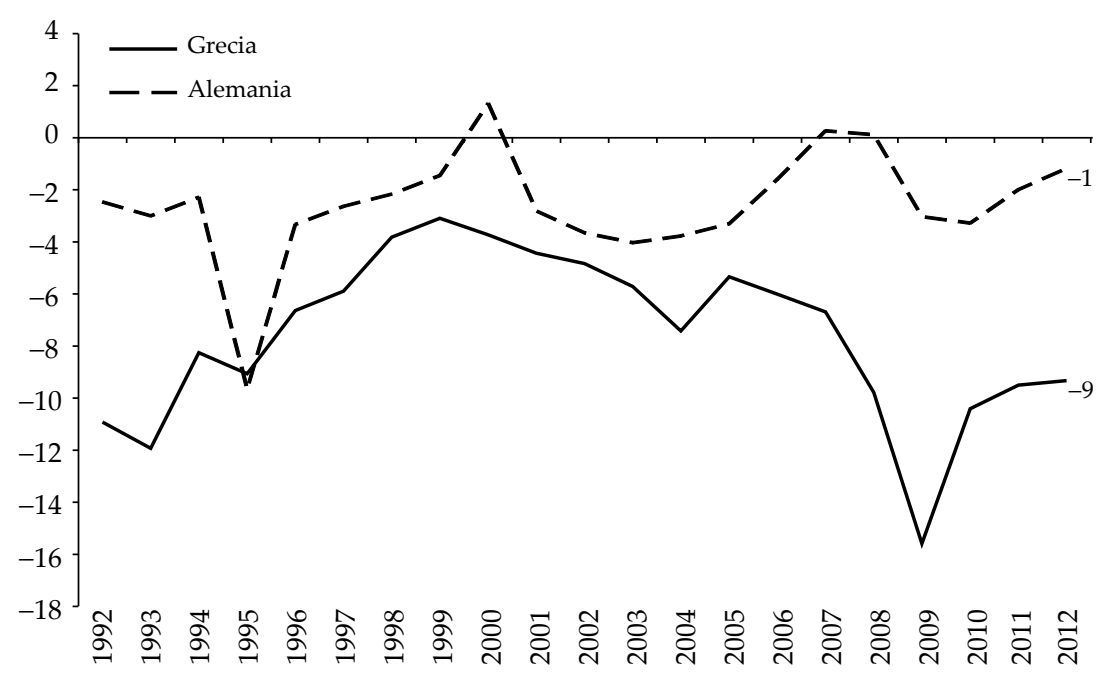

Nota: 2011-2012 son proyecciones.

Fuente: cálculos con base en datos de la Annual Macro-Economic database (AmEco) de la Dirección General de Asuntos Económicos y Financieros de la Comisión Europea.

giro total cuando las políticas de austeridad comenzaron a ser más efectivas en los albores de una amenazante crisis de deuda.

Los déficit crónicos en Grecia se remontan a 1981, cuando el país se unió a la comunidad europea, en cuyo marco se eliminaron las barreras económicas proteccionistas. Esto trajo consigo una caída de los ingresos para el gobierno, situación que habría de empeorar cuando el gobierno encabezado por Andreas Papandreou aplicó una política agresiva de gasto, particularmente en asistencia social, a comienzos de los años ochenta. Adicionalmente, otras causas que agravaron los déficit incluyen los terremotos en los ochentas y noventas, así como disputas con la vecina antigua República Yugoslava de Macedonia y con Turquía en la década de los noventas.

En cuanto al endeudamiento público, ${ }^{1}$ la gráfica 2 muestra que el gobierno griego siempre ha estado en niveles altos, cerca de $100 \%$ del PIB en los años

1 Siendo crecientemente importante el endeudamiento exterior hacia finales de 2011 , cuando $80 \%$ de la deuda pública se tenía con acreedores extranjeros. 
noventa y en los dos mil, antes de dispararse a mayores niveles a partir de la crisis global. De acuerdo con Reinhart y Rogoff (2008), el riesgo de una crisis financiera es significativamente mayor cuando la tasa de la deuda respecto al PIB alcanza o sobrepasa el umbral de 100\%. Esto ocurre, a pesar de que entre 1983 y 2005 la brecha entre las tasas de Grecia y de Alemania se redujo ligeramente. Vale la pena hacer notar también que en los años noventa, pese a las mejoras en el balance de finanzas públicas de Grecia (como ya se mencionó), se mantuvieron altos niveles de endeudamiento en ese periodo. Ello contrasta radicalmente con la situación de Alemania, que siempre ha mantenido niveles de deuda muy bajos en relación con su PIB.

\section{GRÁFICA 2}

\section{Deuda pública neta del gobierno general de Grecia y Alemania, 1992-2012} (como porcentaje del PIB)

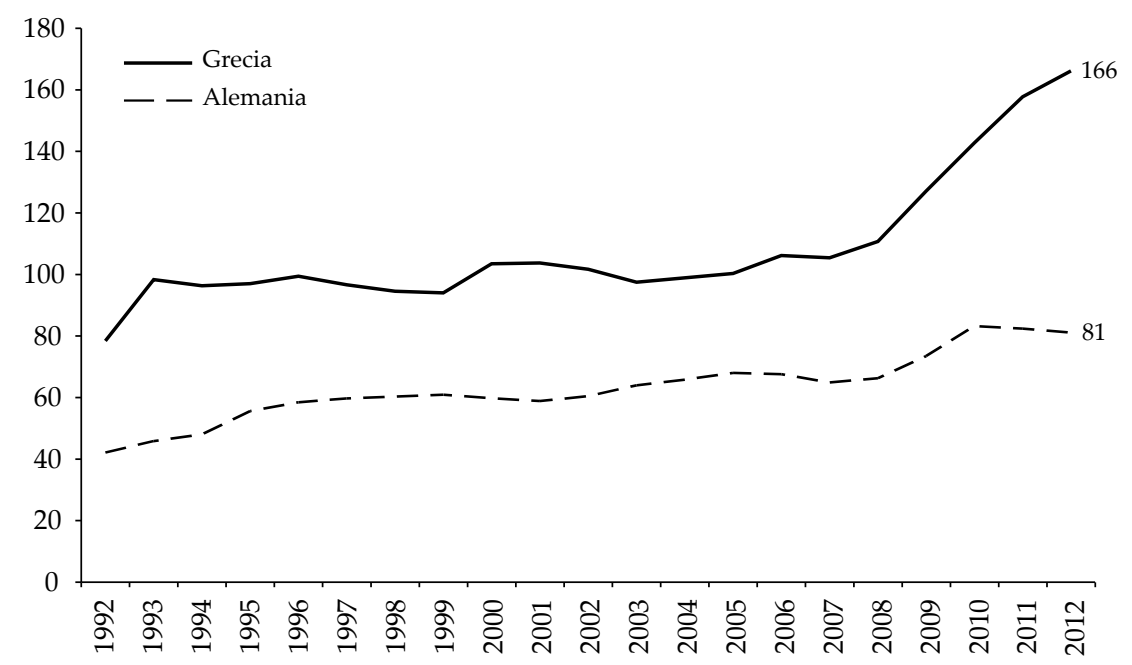

Fuente: cálculos con base en datos de Ameco de la Dirección General de Asuntos Económicos y Financieros de la Comisión Europea.

Respecto a la balanza externa, la gráfica 3 muestra la trayectoria de la balanza en cuenta corriente (como porcentaje del PIB) de Grecia y de Alemania en el periodo 1992-2009. Es evidente que la trayectoria griega exhibe una caída en la tendencia de largo plazo desde mediados de los años noventa y que, en general, parece el reflejo opuesto de la trayectoria alemana. Aunque resulta interesante que de 2000 a 2005 el balance en la cuenta corriente de Grecia griego no se 
deteriora. En general la tendencia corresponde a la condición de exportador hegemónico de Alemania vis-à-vis el resto de la Unión Europea.

\section{GRÁFICA 3}

Balanza en cuenta corriente de Grecia y Alemania, 1992-2009 (como porcentaje del PIB)

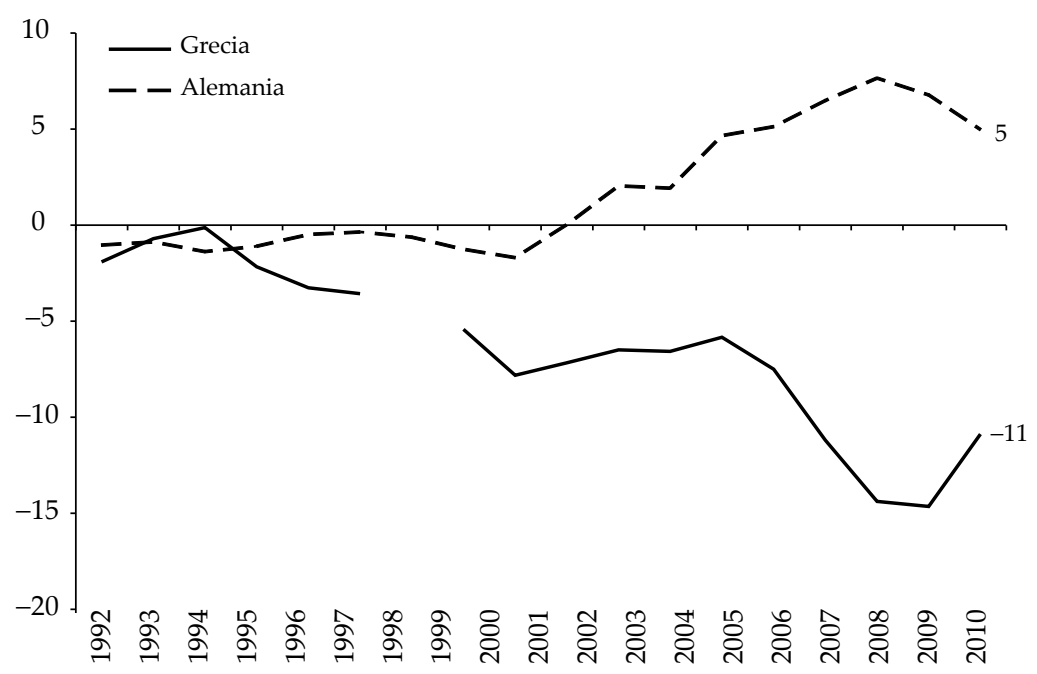

Fuente: cálculo con base en datos de World Development Indicators (wDI) del Banco Mundial.

Referente a los flujos netos de IED, un componente de la balanza de capital, la gráfica 4 indica que antes del nacimiento del euro en 1999, la IED neta como porcentaje del PIB de Grecia fue ligeramente mayor en comparación con Alemania, aunque desde entonces ha sido baja en general. Esto a pesar de los esfuerzos del gobierno griego por atraer inversión extranjera hacia proyectos de infraestructura, como autopistas y el metro para Atenas. También resulta interesante hacer notar que la IED excepcionalmente alta para Alemania en los años previos a 1999, trajo un efecto positivo para su euroización. ${ }^{2}$

2 Una posible explicación de dicha situación en cuenta corriente y en los flujos de IED podría ser la pérdida de competitividad de Alemania, especialmente desde la euroización de Grecia en 2001, lo cual observaremos en el siguiente apartado, cuando abordemos los indicadores de competitividad.. 
GRÁFICA 4

Flujos netos de IED para Grecia y Alemania, 1992-2009

(como porcentaje del PIB)

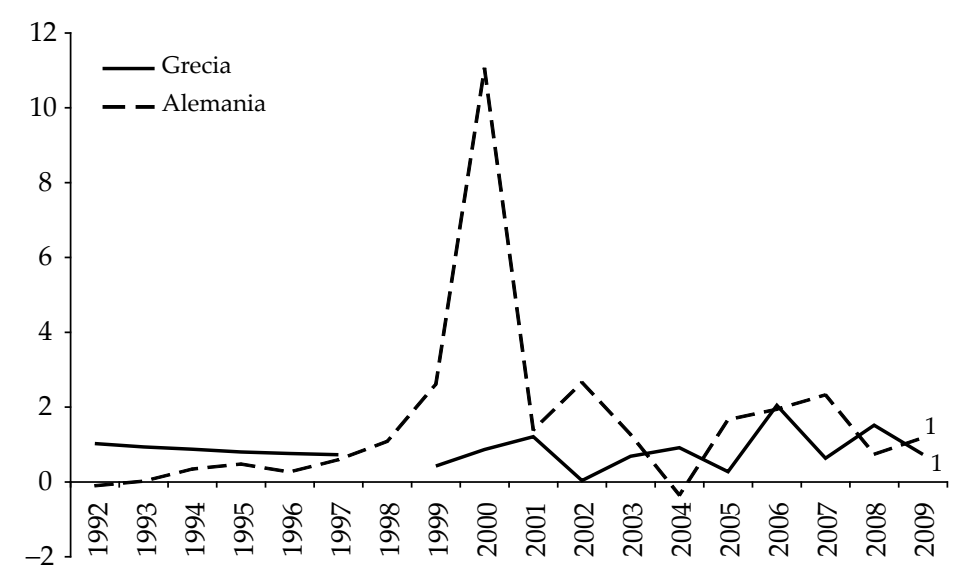

Fuente: cálculo con base en datos de wDi del Banco Mundial.

Por su parte, la gráfica 5 muestra que desde comienzos de los años del 2000 los flujos de capital privado en Grecia se incrementaron significativamente a niveles mayores que los de en Alemania. Dados los niveles relativamente bajos de IED de largo plazo para Grecia, como muestra la gráfica 4, este fenómeno se puede explicar, en primer lugar, por los flujos de capital especulativo de fondos de corto plazo que buscan altos rendimientos en activos griegos, particularmente en valores públicos. Las principales fuentes de los fondos incluyen a Alemania, Países Bajos y Francia. Muy probablemente esto se facilitó por la eliminación del riesgo cambiario al momento en que Grecia se euroizó y por la presencia de una garantía implícita por parte de las autoridades de la eurozona (véase, por ejemplo, de Grauwe y Ji, 2012).

En pocas palabras, con base en los datos previos y con referencia a Alemania, la salud económica de Grecia parecía enviar señales de alarma, lo cual se reflejó en las altas tasas de desempleo en ese país (véase la gráfica 6). Sólo durante el periodo de la burbuja de activos, en los años previos a la crisis mundial, sus tasas de desempleo fueron bajas. 


\section{GrÁFICA 5}

Flujos de capital privado hacia Grecia y Alemania, 1992-2009

(como porcentaje del PIB)

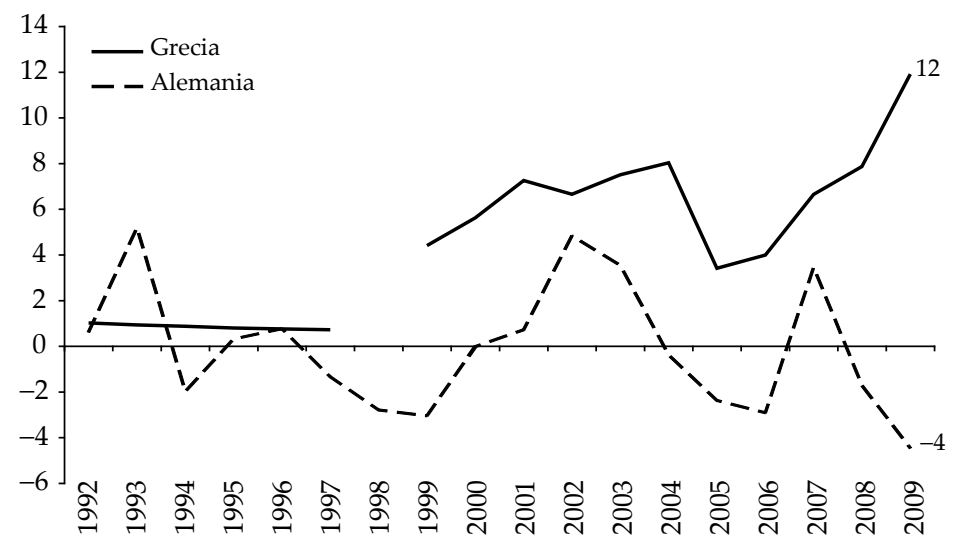

Fuente: cálculo con base en datos de wDi del Banco Mundial.

GrÁFICA 6

Tasas de desempleo, 1992-2010

(porcentajes)

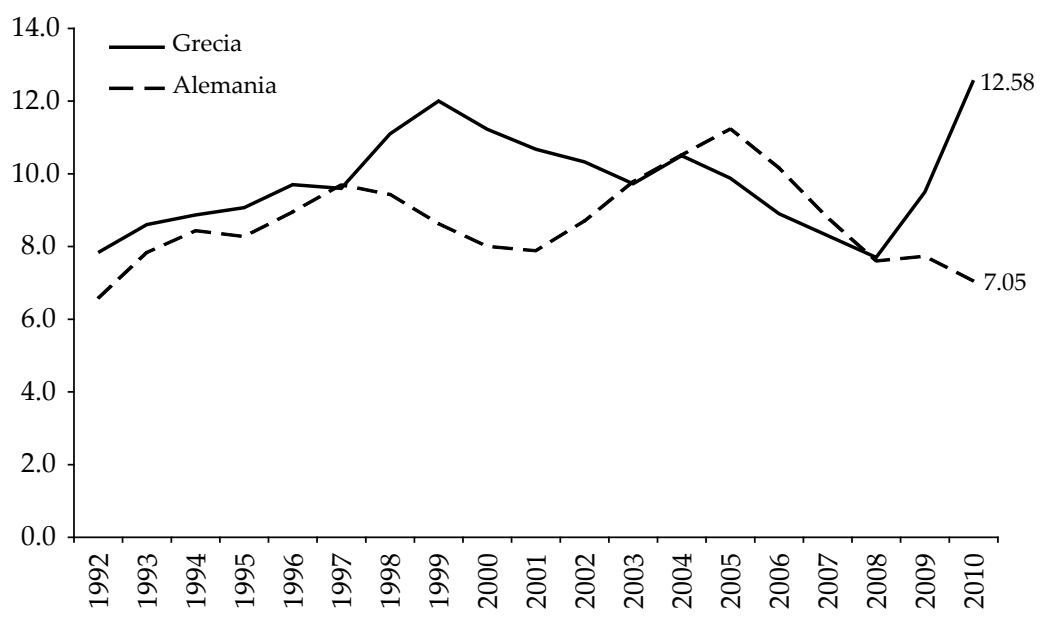

Fuente: cálculo con base en datos de wDi del Banco Mundial.

Sin embargo, y de nueva cuenta, puede decirse que Grecia mantuvo un proceso de crecimiento impulsado por la demanda y no por las exportaciones, como en el caso de Alemania. Además, los impactos de la turbulencia financiera mundial 
y los programas de ajuste acordados con las autoridades europeas pudieron haber exacerbado los problemas de dicho país, de forma que las dificultades que enfrentaba podrían no haber sido de largo plazo.

\section{Evaluación de la competitividad internacional de Grecia}

\section{Tipo de cambio real deflactado por el ipc relativo}

Un determinante importante de competitividad internacional es el tipo de cambio real. Los cambios en esta variable dependen tanto de la tasa relativa de inflación como de las variaciones en el tipo de cambio nominal. Consideremos, en primer lugar, la tasa de inflación subyacente. La gráfica 7 marca las trayectorias del índice de precios al consumidor (IPC) en Grecia, Irlanda, Portugal, Alemania y Estados Unidos de enero de 1992 a noviembre de 2012. A lo largo de este periodo, la inflación [acumulada] fue cercana a 172\% en Grecia, 90\% en Portugal, 62\% en Estados Unidos al igual que Irlanda y 44\% en Alemania.

GRÁFICA 7

Índice de precios al consumidor, 1992:1-2012:11

$(1992: 1=100)$

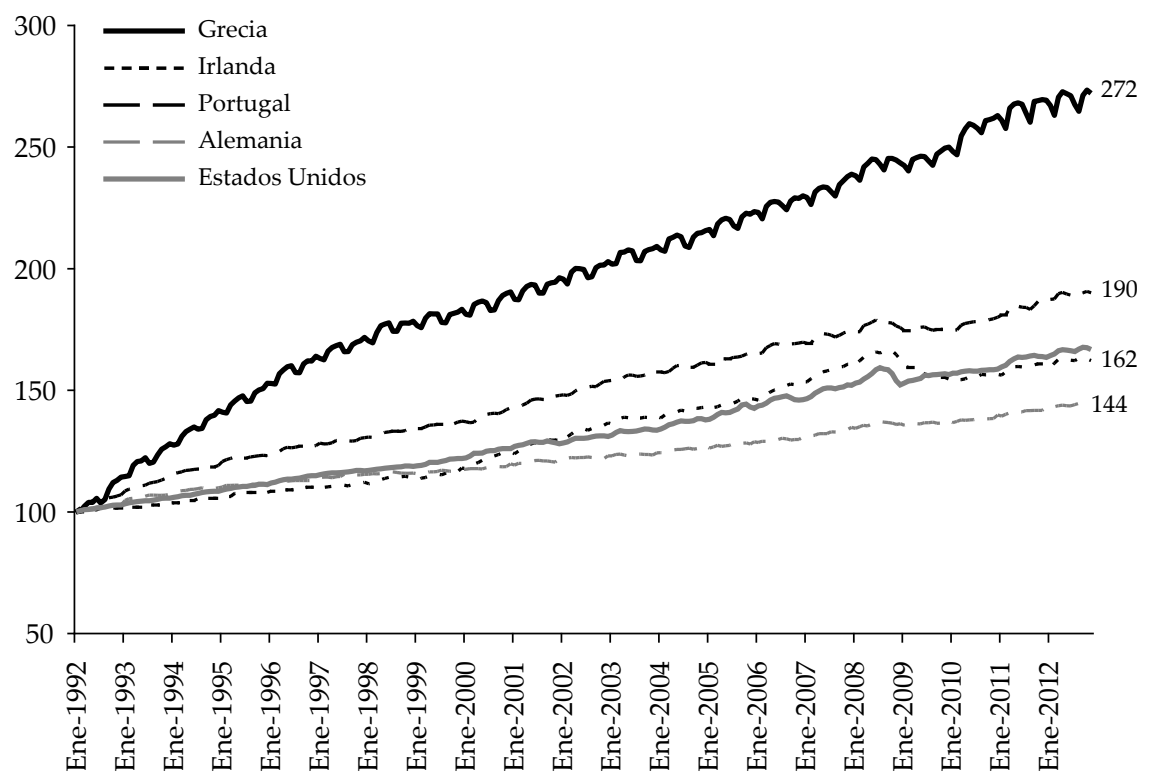

Fuente: cálculo con base en datos de la Organización para la Cooperación y Desarrollo Económicos (OCDE). 
La gráfica 8 presenta el tipo de cambio nominal en dólares (sin deflactar) para Grecia, Alemania, Portugal e Irlanda durante el mismo periodo. Antes del nacimiento del euro en 1999, y no obstante algunos altibajos, es claro que el dracma se movió visiblemente a la par del resto de las monedas, aunque ha sido cada vez más barata, de hecho la más barata, en términos de dólares. Específicamente, a lo largo del sub-periodo 1992-1999, el dracma se depreció en cerca de 51\% respecto al dólar estadounidense, mientras que el marco alemán permaneció casi sin cambios.

\section{GráfICA 8}

Tasa nominal del dólar, 1992:1-2012:12

$(1992: 1=100)$

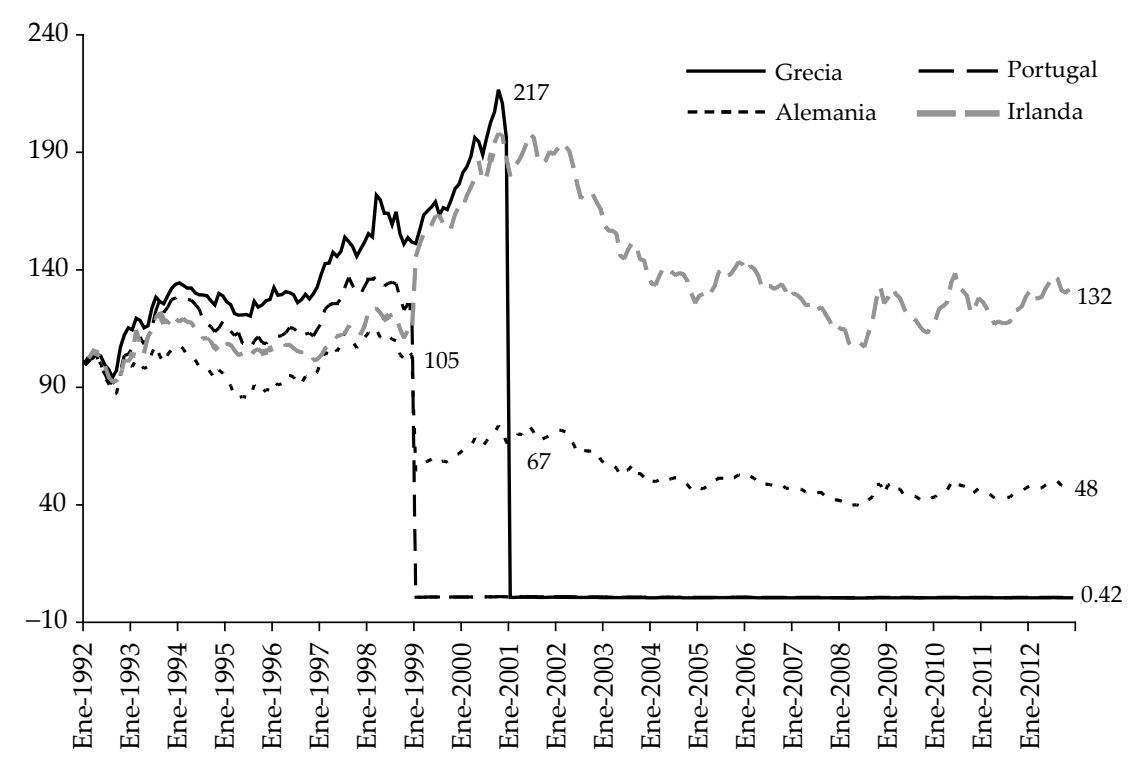

Fuente: cálculo con base en datos del Fondo Monetario Internacional (FMI).

Cuando consideramos el periodo 1992-2000, observamos que el dracma se depreció cerca de $117 \%$ en relación con el dólar, mientras que el marco más bien se apreció cerca de 33\% frente al dólar, debido a la euroización. En suma, en relación con esta última moneda, el marco se apreció 150 puntos porcentuales más en comparación con el dracma. Por tanto, previo a la euroización de Grecia, el país había sido significativamente más competitivo que Alemania (y Portugal), sin embargo, pasó a ser significativamente menos competitivo con la euroización en 2001. 
Tomando el periodo muestra de 1992-2012 como un todo, la moneda griega, similar con la portuguesa, se apreció efectivamente $100 \%$ en relación con el dólar; la moneda alemana lo hizo en cerca de 50\%, mientras que la de Irlanda se depreció en casi 30\%. Al agregar el diferencial inflacionario del IPC de Estados Unidos al cambio en la tasa nominal en dólares, la apreciación real (aproximada) de la moneda griega fue de $210 \%$ frente al dólar para todo el periodo. Por su parte, la apreciación real de la moneda alemana respecto al dólar fue tan sólo de $30 \%$ en el mismo periodo.

Si deflactamos doblemente la tasa nominal en dólares por los respectivos IPC, la gráfica 9 muestra trayectorias altamente sincronizadas de las monedas europeas previo al nacimiento del euro en 1999, para posteriormente distanciarse, aunque paralelamente desde 1999 hasta 2000, y divergir significativamente en el caso de Grecia y Alemania, cuando el euro reemplazó la dracma en 2001. La misma divergencia sucedió entre Alemania y Portugal e Irlanda, quienes adoptaron el euro a principios de 1999.

\section{GrÁFICA 9}

Tasa real del dólar deflactada por el IPC, 1992:1-2012:11

$(1992: 1=100)$

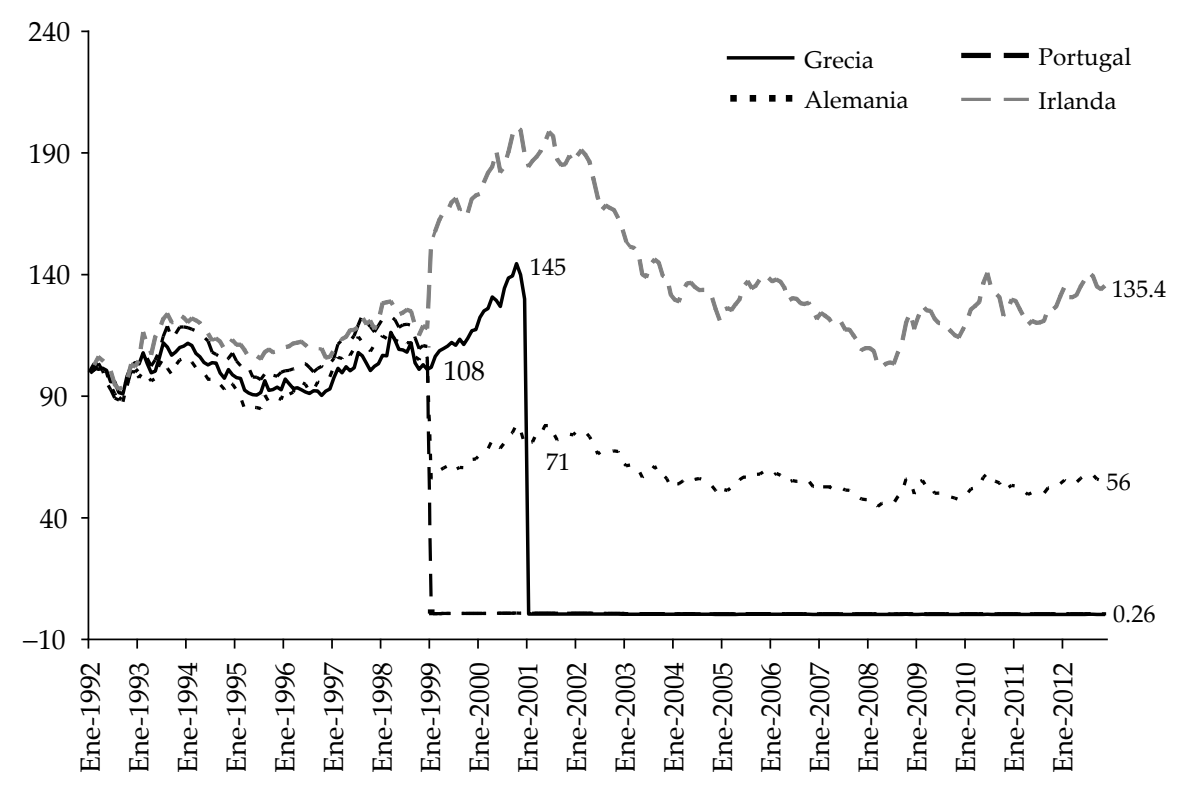

Fuente: cálculo con base en datos del FMI. 
Con más detalle para el periodo 2001 a 2012, la gráfica 10 pone al descubierto que si bien los movimientos de las tasas han sido paralelos (resultado de la unificación de los tipos de cambio reales), la trayectoria griega es consistentemente la más baja entre las del resto de las monedas. Esto implica que en términos reales es crecientemente más caro para un dólar estadounidense comprar en Grecia que en Alemania, Portugal o Irlanda. Esto se observa cuando se utiliza enero de 2001 como base y punto de referencia. Las brechas son incluso mayores si utilizamos 1992 como año base, como muestra la gráfica 9.

Gráfica 10

Tasa real del dólar deflactada por el IPC, 2001:1-2012:11 $(2001: 1=100)$

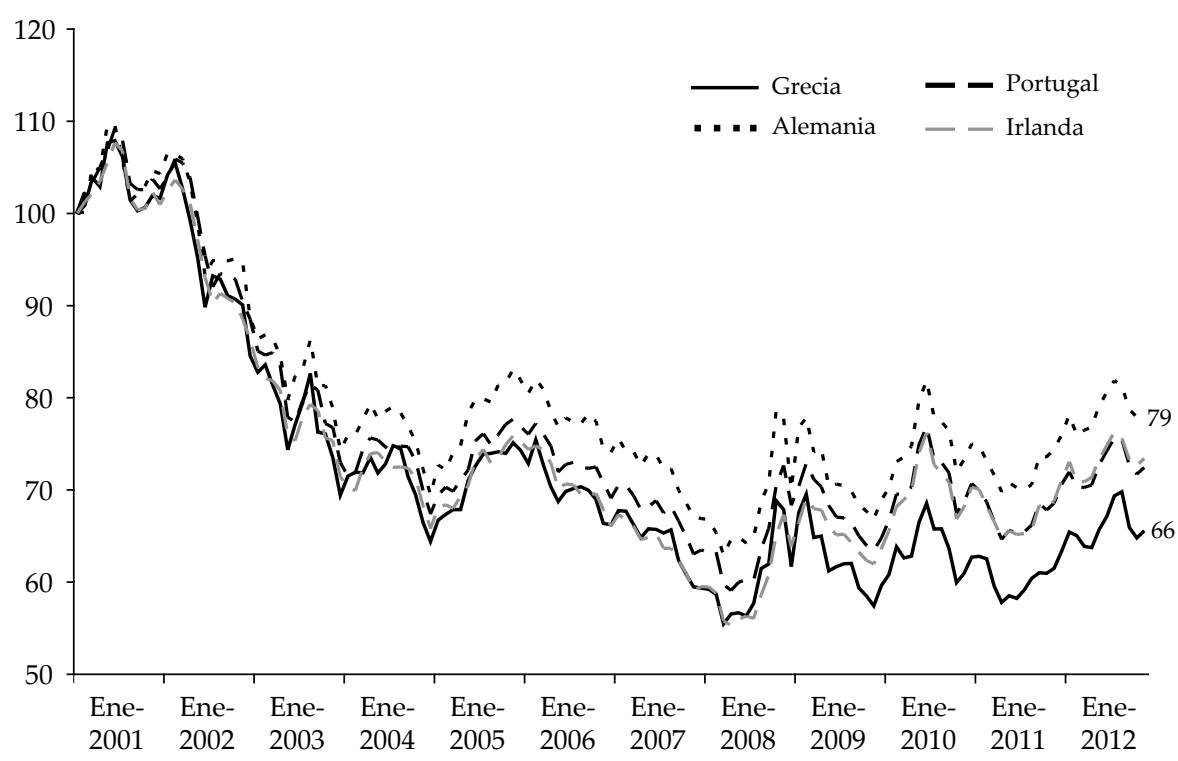

Fuente: cálculo con base en datos del FMI.

En resumen, la relación del tipo de cambio real entre los países se puede dividir en tres fases. En la primera (1992-1998) las trayectorias están prácticamente unificadas y sincronizadas. En la segunda (1999-2000) Grecia pierde competitividad en relación con Irlanda, aunque es más competitiva respecto a Alemania y Portugal debido a una apreciación nominal significativa de las monedas alemana y portuguesa frente al dólar en 1999. En la tercera (2001 a 2012) Grecia es más cara que Alemania, Portugal e Irlanda dada la apreciación nominal excepcional- 
mente alta de la moneda griega frente al dólar, a consecuencia de la euroización de Grecia en 2001 y a una mayor tasa de inflación en dicho país.

\section{Tipos reales de cambio deflactados por costos unitarios laborales}

Para verificar los cálculos anteriores de los tipos de cambio reales deflactados con base en el IPC, considérense los costos unitarios de trabajo estimados por la Organización para la Cooperación y Desarrollo Económicos (OCDE), principalmente para la manufactura. Utilizamos datos anuales debido a que están disponibles para todos los países en cuestión. La gráfica 11 revela que los costos unitarios de trabajo en Grecia se incrementaron 170\%, mientras que en Alemania tan sólo en 6\%. Por su parte, los de Estados Unidos e Irlanda cayeron 17\% y los de Portugal aumentaron ligeramente por encima de los de Alemania; no obstante, fueron más bajos en comparación con los de Grecia. Así, los costos unitarios de trabajo en la manufactura en Grecia se incrementaron respecto a los de Estados Unidos en 187 puntos porcentuales y en relación con los de Alemania en 164 puntos porcentuales.

\section{GRÁfICA 11}

Costos unitarios del trabajo en la manufactura, 1992-2010

$(1992=100)$

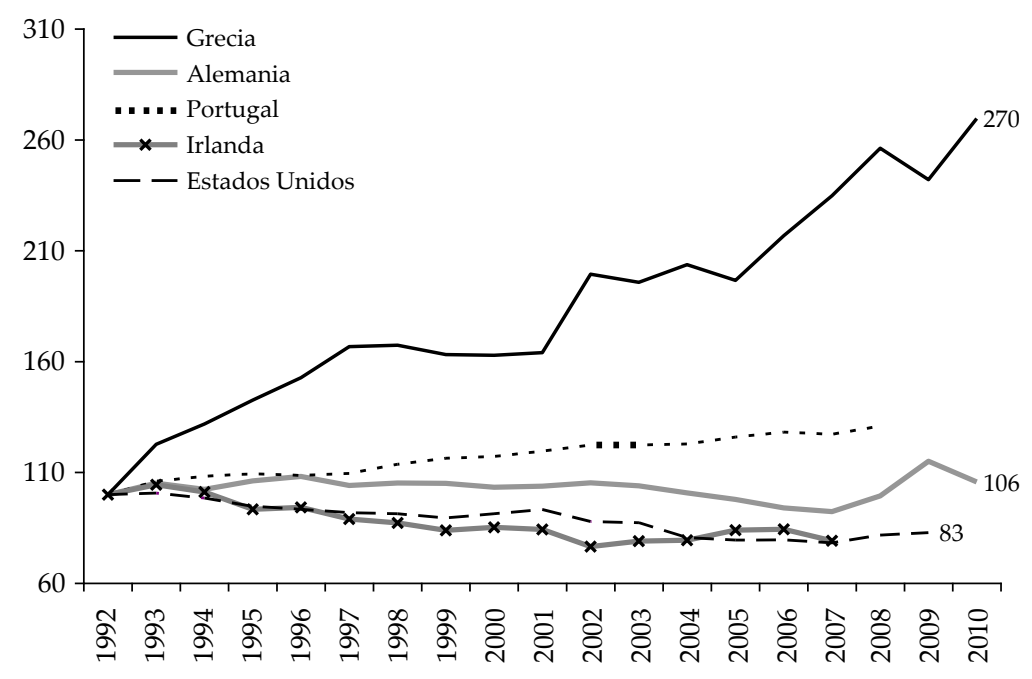

Fuente: cálculo con base en datos de la Organización para la Cooperación y Desarrollo Económicos (OCDE). 
Si deflactamos doblemente la tasa nominal del dólar con los costos unitarios de trabajo en la manufactura, la gráfica 12 indica casi tres fases en las trayectorias del tipo de cambio real. En la primera fase (1992-1998), previo al lanzamiento del euro, un dólar podía comprar más unidades de trabajo en Irlanda, Portugal y Alemania en comparación con Grecia. Durante la segunda (1999-2000), antes de que el euro reemplazara al dracma, los costos unitarios de trabajo eran más bajos en Grecia respecto a los de Portugal y Alemania, aunque no más que en Irlanda. En la tercera (2001-2009) los costos del trabajo en Irlanda y Alemania son considerablemente más bajos en relación con los de Grecia y Portugal (siendo 1992 el año base).

\section{GrÁfica 12}

\section{Tasa real del dólar deflactada por los costos unitarios} de trabajo relativos, 1992-2010

$(1992=100)$

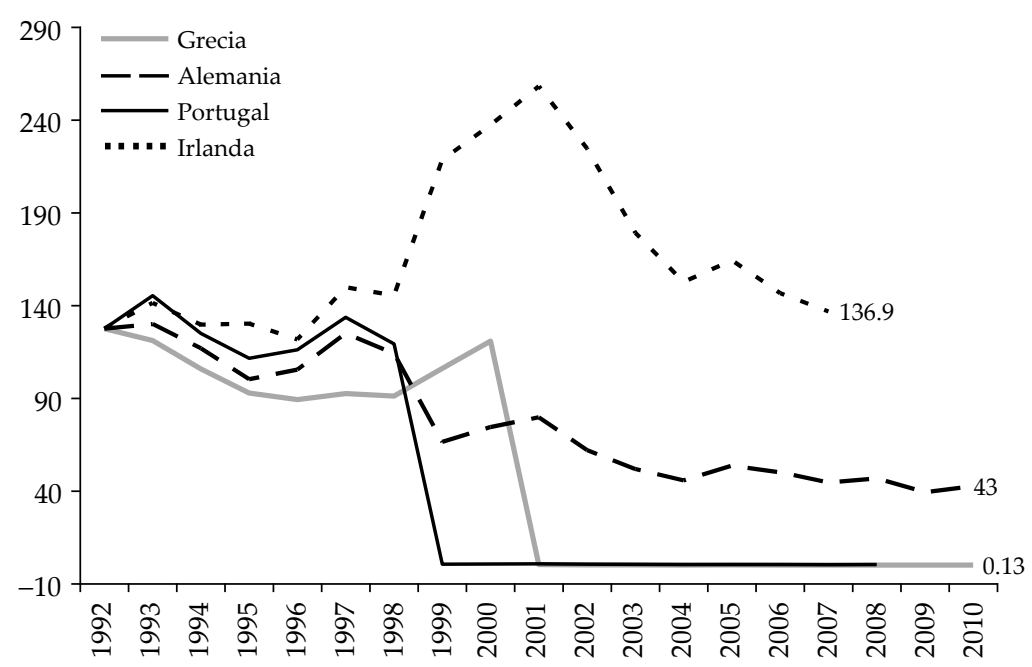

Fuente: cálculo con base en datos de la ocDE.

En la totalidad del periodo, 1992-2010, los costos del trabajo en dólares en Grecia se apreciaron en 43 puntos porcentuales por encima de los de Alemania y en 137 puntos porcentuales por encima de los de Irlanda.

¿Podría uno explicar la competitividad relativa de Alemania respecto a la de Grecia por el superior crecimiento de la productividad alemana? No realmente, la gráfica 13 muestra los movimientos de la productividad del trabajo en Grecia 
y Alemania. Es claro que desde 2003 Grecia sobrepasó a Alemania en términos de crecimiento de productividad. Empero, la competitividad de Irlanda con relación a la de Grecia puede ser explicada por mayor productividad.

GRÁFICA 13

Productividad de la fuerza trabajo, 1992-2011

$(1992=100)$

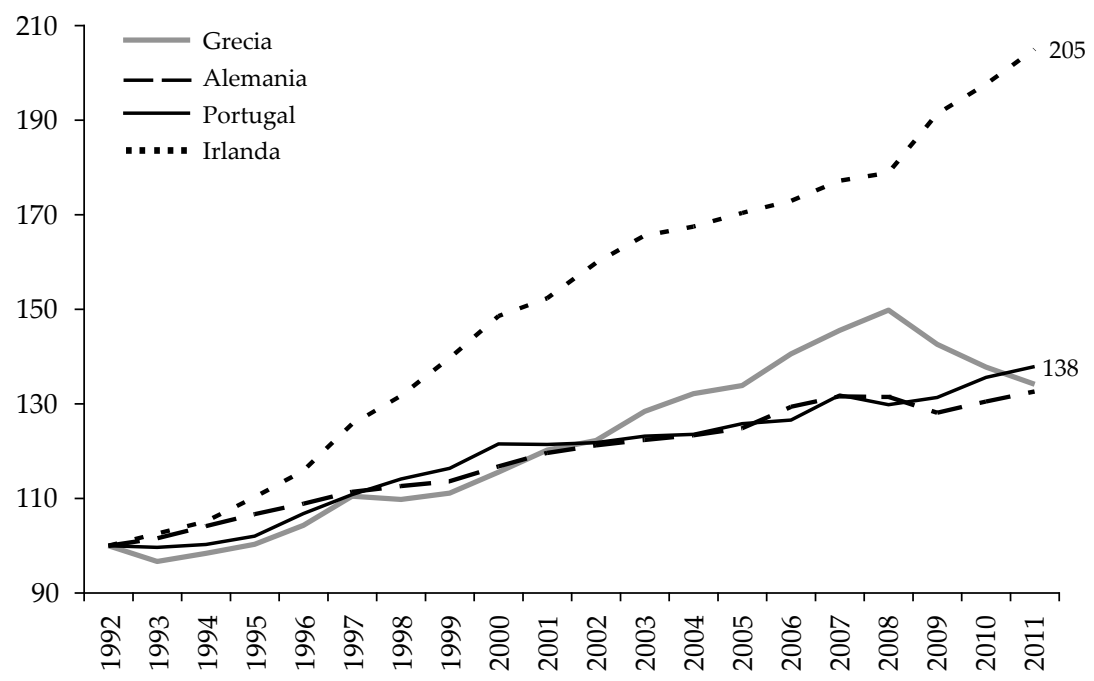

Fuente: cálculo con base en datos de la ocDE.

Uniendo todas las piezas, la evidencia que hemos discutido en esta sección parece indicar que la pérdida de competitividad de Grecia frente a Alemania se debe, en gran medida, a la excesiva apreciación del tipo de cambio nominal griego respecto al dólar al momento en que Grecia unificó su moneda con la de Alemania, y no por un mayor crecimiento de la productividad en esta última. Lejos de compensar los ajustes en los precios internos, el euro seguirá sobrevaluándose sustancialmente en Grecia.

Asimismo, la pérdida del instrumento de política del tipo de cambio en el caso de Grecia y la presencia simultánea de una más alta tasa de inflación, sugieren la creación de un mecanismo europeo que compense la consecuente pérdida de competitividad. De hecho, la tasa más alta de inflación en este país puede ser la consecuencia de la estructura oligopólica de su organización productiva. 


\section{CONFORMACIÓN CON LOS CRITERIOS DE LAS ZMO}

En esta sección se evalúa a Grecia de acuerdo con el criterio de convergencia que sugiere la teoría de las ZMO. Como en las secciones previas, las comparaciones las hacemos en relación con Portugal e Irlanda. A manera de introducción, en primer lugar haremos una rápida revisión de la teoría de las ZMO.

Las bases de la teoría de las ZMo las sentaron Mundell (1961) y McKinnon (1963), y posteriormente las refinaron Kenen (1969) y Krugman (1990). Básicamente, esta teoría establece los criterios en cuyo marco un país o una economía pueden obtener grandes beneficios o reducir sustancialmente los costos que implica unirse a una zona monetaria. Como resume Boreiko (2003: 315):

La teoría de las ZMO aborda los beneficios y los costos asociados a la adopción de una moneda única, los cuales dependen del grado de convergencia de las economías. Los beneficios están asociados con el aprovechamiento económico de los costos de intercambio y de la importación de la credibilidad del banco central de la unión, reduciendo con ello las expectativas y el nivel de la inflación. En cuanto a los costos asociados, son esencialmente los opuestos a los beneficios de tener políticas monetaria y cambiaria independientes, las cuales son útiles como medios para responder a las sacudidas que son asimétricas entre las posibles partes en la unión monetaria (Traducción del original en inglés).

De acuerdo con los trabajos recientes de Quah (2012a; 2012b; 2013b), Quah y Crowley (2010; 2012a; 2012b) y Quah e Ismail (2012), los criterios de las ZMO que aquí investigamos son: intensidad del comercio bilateral, simetría del ciclo económico, sincronización de la tasa de interés real, convergencia inflacionaria y flexibilidad del mercado laboral. La eficacia de estos criterios en el contexto de la eurozona la hicieron evidente Artis y Zhang (2002) al seleccionar a Portugal, Italia, Grecia y España como un grupo de países cuyas características eran las menos similares en términos de ZMO respecto a las de Alemania.

Los cuatro primeros criterios se miden respecto a un país de referencia; en este caso, y para reiterar, Alemania, el banquero central de facto de la eurozona. Al mismo tiempo, resulta atractivo comparar las relaciones de Grecia con Alemania con relación a las de Estados Unidos, una economía dominante en el Atlántico Norte. 


\section{Intensidad del comercio bilateral}

Mundell (1961) destaca el comercio como precondición para evaluar los beneficios y bienestar social que traen consigo tasas de intercambio comercial estables. McKinnon (1963) concuerda y señala que los países con grandes volúmenes de comercio entre sí son buenos candidatos para la integración monetaria ya que pueden obtenerse máximos beneficios en términos de ahorros en los costos de transacción y de los tipos de cambio. Empíricamente, Bayoumi y Eichengreen (1997) detectaron que los países europeos que alcanzan los mayores volúmenes de comercio bilateral se caracterizan por tener las mejores condiciones para una unión monetaria.

En esta línea, resulta convincente observar este ángulo como un criterio para evaluar si la adopción que se hizo en Grecia de las políticas de Alemania fue una acción apropiada. Para ello, la apertura comercial se mide en términos de intensidad de comercio bilateral, $\left(x_{i, r}+m_{i, r}\right) /\left(x_{i}+m_{i}\right)$ donde $x_{i}$ y $m_{i}$ son las exportaciones e importaciones de bienes griegas, mientras que el subíndice $r$ indica el destino de o fuente de Alemania o Estados Unidos. El valor para cada año a lo largo del periodo 1992-2011 se muestra en la gráfica 14.

La gráfica indica que no obstante ciertos altibajos, la apertura comercial de Grecia con los Estados Unidos es consistentemente más alta que con Alemania. De hecho la importancia de Alemania como socio comercial ha venido decayendo a lo largo del periodo en cuestión. En otro aspecto, si observamos el patrón de comercio de largo plazo con los Estados Unidos, parece mostrar un desplazamiento ascendente a lo largo de los años de 1990 y una tendencia descendente en los de 2000, a la par del incremento de competitividad de Grecia en relación con los Estados Unidos en el primer periodo y una caída de competitividad al momento en que el país griego adoptó el euro en el segundo periodo. Si uno utiliza el porcentaje del comercio alemán en el comercio total griego, en comparación con el de Estados Unidos, entre 2000 y 2006, la apertura comercial de Grecia con Estados Unidos puede relacionársela con la tendencia del PIB estadounidense.

Puede hacerse una observación similar para Portugal e Irlanda, cuya apertura comercial con Estados Unidos ha sido mucho mayor que con Alemania. Mientras la mayor apertura de Portugal hacia Estados Unidos ha venido decayendo en años recientes, la de Irlanda se ha incrementado marcadamente. 
GrÁFICA 14

Apertura comercial de Grecia con Estados Unidos y Alemania, 1992-2011

$(1992=100)$
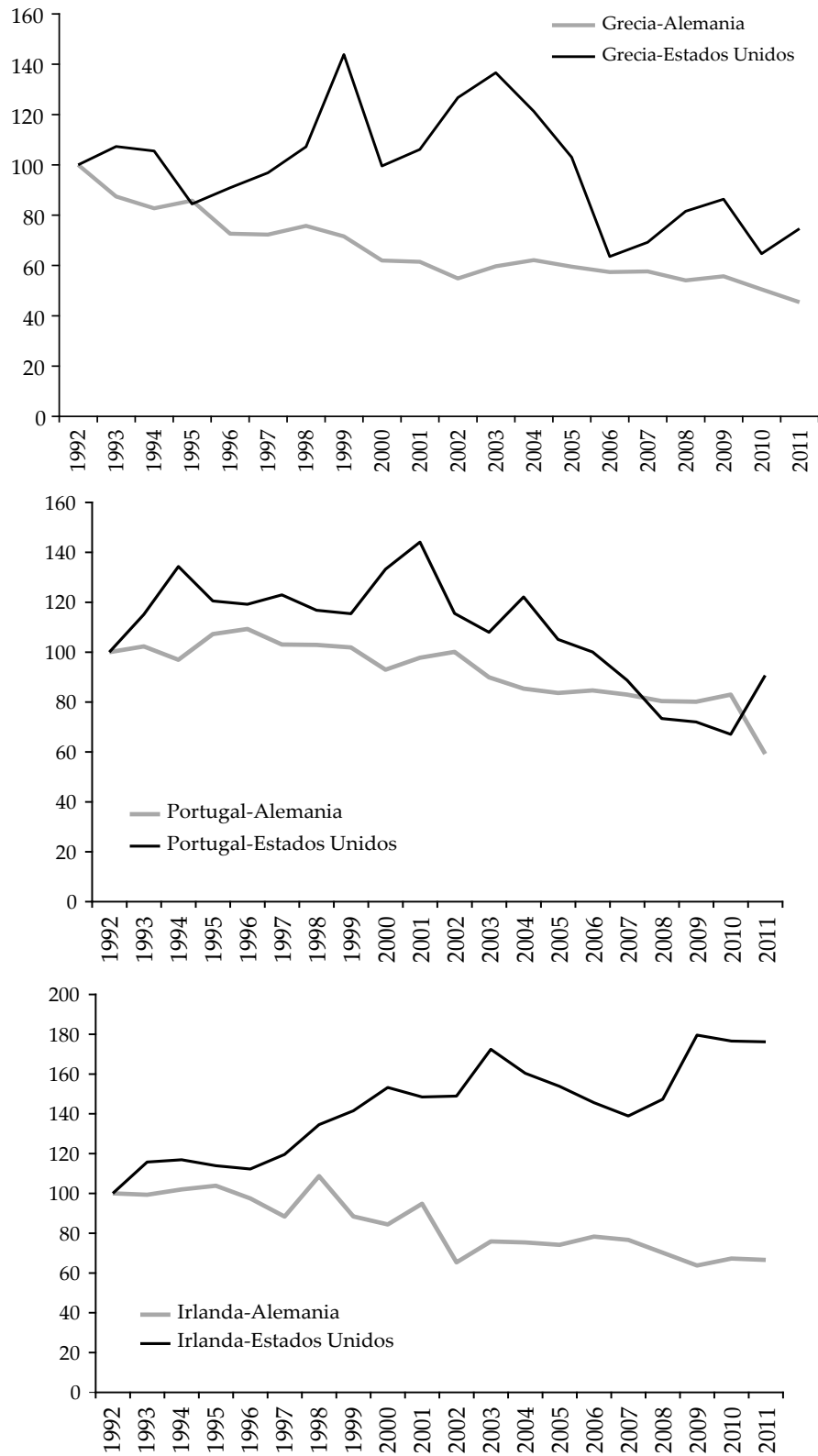

Fuente: cálculo con base en datos de Direction of Trade Statistics (Dотs) del FмI. 


\section{Simetría del ciclo económico}

Cuando los ciclos económicos son sustancialmente sincrónicos entre zonas monetarias, pierde creciente importancia el papel que desempeña la flexibilidad de los tipos de cambio como amortiguadores de las sacudidas de la demanda asimétrica o presiones de oferta a través de las zonas. De forma que, para el caso griego, entre mayor sea la sincronía del ciclo económico con Alemania (o Estados Unidos), mayores serán las posibilidades de unificación monetaria con Alemania (o Estados Unidos). En términos de medición, se ha hecho popular aplicar este criterio de acuerdo con la sincronía de los ciclos económicos mediante la evaluación de correlaciones de los componentes cíclicos del producto. Para inferir los ciclos, se adopta el método de Gerlach (1998) y Baxter y Stockman (1989) que elimina las tendencias existentes en los componentes cíclicos de las series trimestrales del PIB real, recurriendo al uso del filtro HodrickPrescott (H-P).

La gráfica 15 muestra las correlaciones del ciclo económico de Grecia con Alemania y Estados Unidos de enero de 1992 a enero de 2011. Se utiliza el índice mensual de precios industriales (IPI) para establecer las variaciones de producto. También se muestran los 12 meses correspondientes a Portugal e Irlanda. Asimismo, se muestra, en porcentajes, el mayor número de veces en que hay correlación con Alemania en comparación con Estados Unidos.

Como muestran la gráfica y el porcentaje, Grecia tiene prácticamente mayor sincronía con Alemania que con los Estados Unidos a lo largo del periodo, siendo $70.4 \%$ mayor número de veces en que hay correlación con Alemania. En lo que corresponde a Portugal e Irlanda, puede observarse algo muy similar, si bien con menores porcentajes, a saber, 60 y 58.3 por ciento respectivamente. Con esta evidencia, la simetría del ciclo económico griego con el de Alemania es mayor que con el de Estados Unidos cuando se compara con el de Portugal e Irlanda.

\section{Tasa de interés real simetría del ciclo}

Si bien no aparece como uno de los criterios en los que se basa la teoría de las ZMO, de acuerdo con Artis y Zhang (2002) este factor se indica mediante un argumento de "preferencia revelada". Si la política monetaria de un país ha 
GráficA 15

Correlaciones del ciclo económico con Alemania y Estados Unidos, 1992:1-2011:1
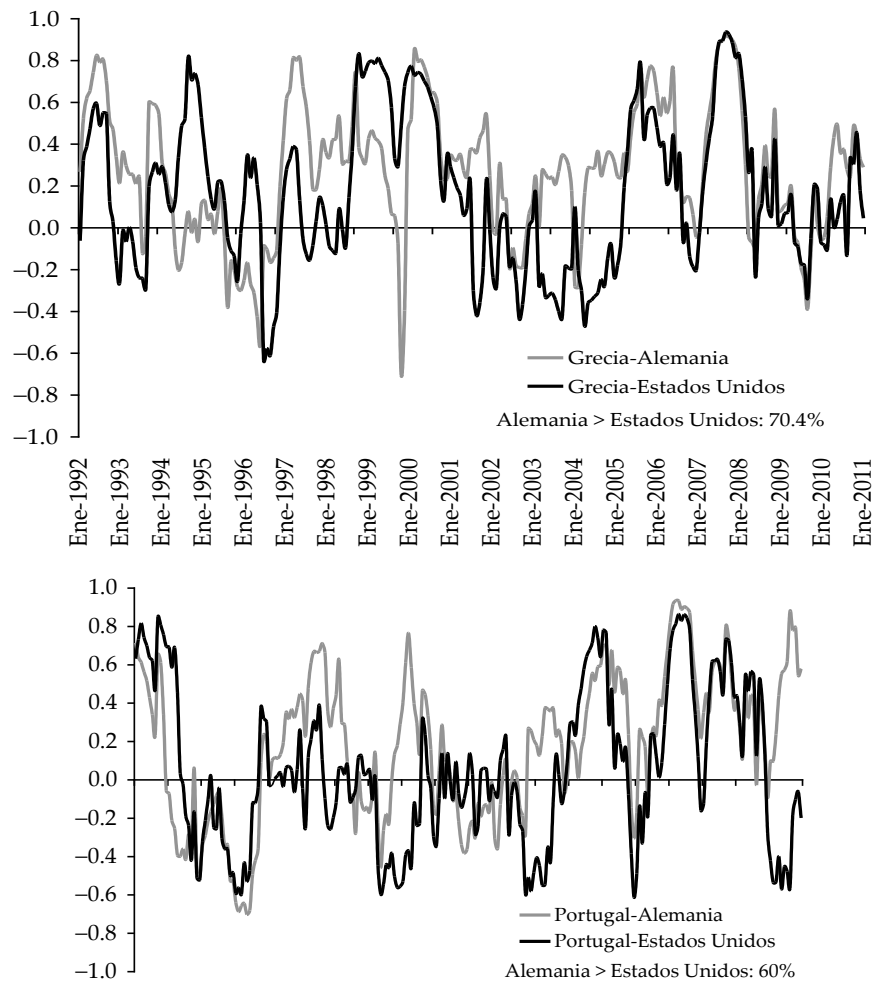

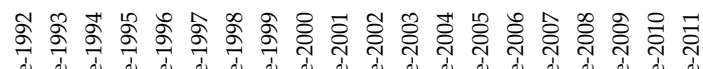

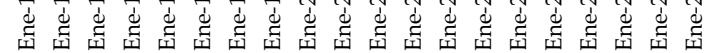

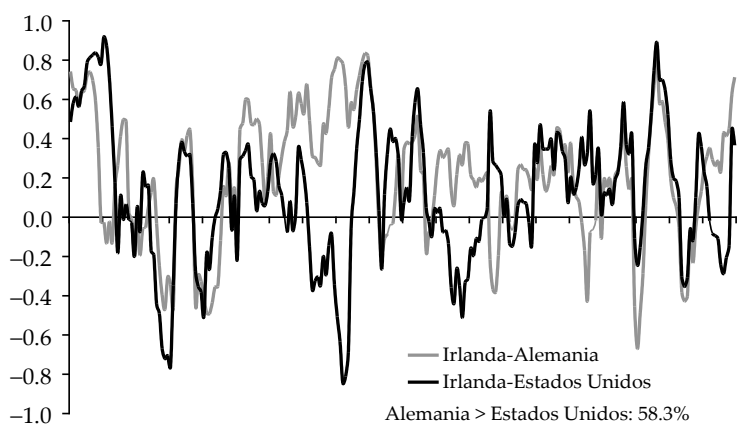

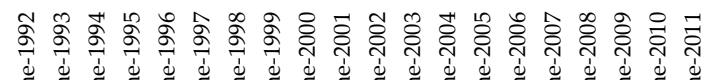

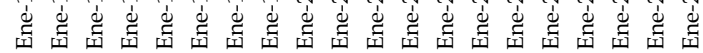

Fuente: cálculos con base en datos de la ocDE. 
diferido un poco históricamente respecto a la de un país de referencia, el costo de ceder independencia monetaria sería bajo, de forma que la sincronización en las tasas de interés reales se podría interpretar como un indicador de coordinación de política monetaria. Siguiendo a Quah y Crowley (2010), mediante la aplicación del filtro H-P se eliminan las tendencias existentes en las series de tasa de interés real para obtener los ciclos, donde la sincronía la indican correlaciones entre los ciclos. Para calcular tasas de interés reales se utilizan las tasas de corto plazo en el mercado de dinero y las tasas de inflación del IPC. En la gráfica 16 se muestran los coeficientes de correlación de 12 meses con Alemania y Estados Unidos a lo largo del periodo 2001:1-2012:1. También aparece, en porcentaje, la mayor cantidad de veces en que hay correlación con Alemania en comparación con Estados Unidos. El periodo queda restringido a la disponibilidad de datos de los países.

Como muestra la gráfica, el dominio relativo de Alemania y los Estados Unidos difiere dependiendo del periodo. Específicamente para Grecia, durante los primeros años posteriores a la euroización de 1999, la simetría con Alemania fue mayor, sin embargo, para los años subsiguientes y hasta finales de 2000 -que coincide con la crisis de las subprime en los Estados Unidos- el grado de simetría con este país fue mayor. Durante 2010-2011, en los momentos de pánico por la deuda del euro, hubo una mayor convergencia relativa con Alemania respecto a con los Estados Unidos. La relativamente coordinada política monetaria de Grecia con los Estados Unidos en el periodo que desembocó en la crisis de las subprime pudo haber ayudado a alimentar las burbujas especulativas en Grecia. Así, no es de sorprender que el valor porcentual de mayor sincronía con Alemania respecto a Estados Unidos tan sólo fuera de 51.9\%. Esto indica casi igual dominio de la política monetaria de los Estados Unidos sobre Grecia, en comparación con la de Alemania. Para aclarar, aun si Grecia y Alemania comparten de hecho las mismas tasas de interés nominales después de la euroización, sus ciclos de tasa de interés "real" pueden divergir debido a diferencia en las tasas de inflación.

En lo que a Portugal e Irlanda se refiere, con las mismas medidas, el grado de sincronía con Estados Unidos ha sido de hecho ligeramente mayor respecto a su sincronía con Alemania. 
GrÁFICA 16

Correlaciones del ciclo de la tasa de interés real con Alemania y Estados Unidos, 2001:1-2012:1
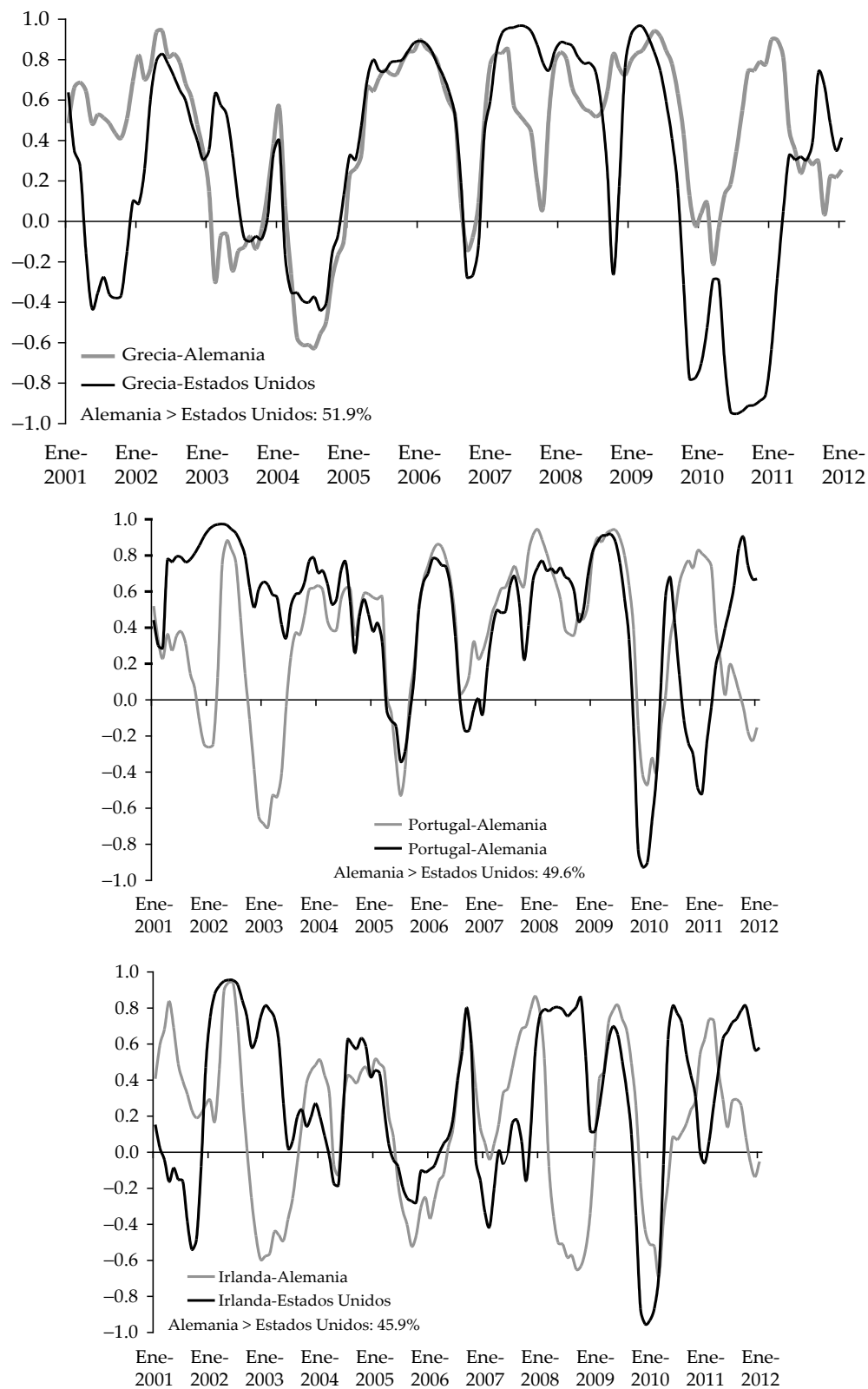

Fuente: cálculo con base en datos de la OCDE. 


\section{Convergencia de inflación}

Como lo señalan Artis y Zhang (2002), la literatura económica tradicional de las ZMO se originó durante la era de la economía del "precio-fijo", de forma que introducir la convergencia de inflación como criterio se puede entender simplemente como una normalización apropiada. Desde otro punto de vista, dado que tasas de inflación similares resultan de similitudes en políticas monetarias y fiscales y en estructura económica, puede presumirse que el costo de unirse a una zona monetaria será bajo si las tasas de inflación son similares entre los integrantes (Nguyen, 2007). La convergencia en inflación entre países también refleja similitud en costos del trabajo y agresividad de los sindicatos, lo que implica menor necesidad de flexibilidad de tipos nominales de cambio para ajustar desequilibrios en cuenta corriente (Fleming, 1971).

Este criterio se lo cuantifica con diferencial absoluto de inflación del IPC, $\left|x_{i}-x_{r}\right|$ donde $x_{i}$ y $x_{r}$ son las respectivas tasas de inflación en Grecia, Portugal o Irlanda, y Alemania o Estados Unidos. Se utiliza el valor absoluto debido a que aquí nos interesa la magnitud. Diferencias bajas indican mayor convergencia en inflación y viceversa.

La gráfica 17 presenta las diferencias de enero de 1992 a diciembre de 2012. Es obvio que la inflación en Grecia fue convergiendo con la de Alemania y los Estados Unidos a lo largo de los años, particularmente desde el advenimiento del euro en 1999. Específicamente, la inflación en Grecia ha sido en general más paralela a la de los Estados Unidos que a la de Alemania, especialmente en la reciente década, no obstante la aplicación del criterio de estabilidad de precios de Maastricht. Se pueden observar hallazgos similares para Portugal e Irlanda para los cuales, en porciones significativas del periodo, la convergencia de inflación con la de los Estados Unidos ha sido mayor en comparación con la de Alemania.

\section{Flexibilidad del mercado laboral}

Ingram (1962) y Kenen (1969) propusieron que la flexibilidad en los mercados laborales nacionales tiene la misma importancia que la movilidad de la fuerza de trabajo entre naciones - idea que popularizó Mundell (1961) y que recientemente revisó Krugman (2012), a la luz de la crisis de la eurozona- para equilibrar distorsiones en los mercados laborales. La hipótesis es: a mayor flexibilidad de 
GrÁfICA 17

Convergencia de inflación con Alemania y Estados Unidos, 1992:1-2012:12 (porcentajes)
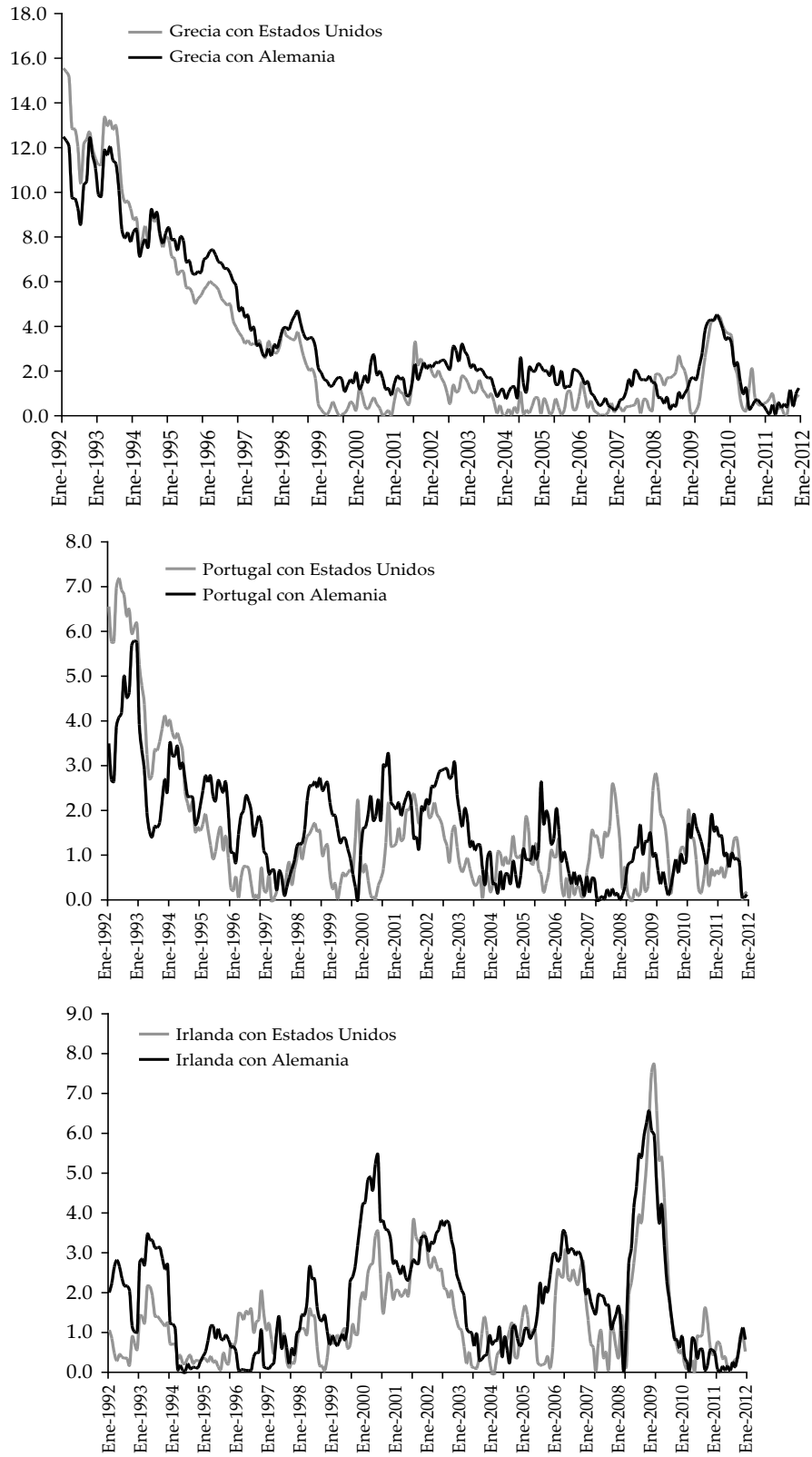

Fuente: cálculo con base en datos de la ocDE. 
los mercados laborales, mayores serán las posibilidades de recuperación del empleo después de sacudidas severas; de ahí que sea más deseable fijar las tasas de interés. Siguiendo a Artis y Zhang (2002), utilizamos un índice de la OCDE para medir la rigurosidad de la protección del empleo, considerando que entre menor sea el índice de protección mayor será la flexibilidad.

La gráfica 18 muestra que el mercado laboral griego es menos elástico en comparación con el alemán, no obstante que hay creciente flexibilidad en el primero desde inicios de los años 2000. Sin embargo, Grecia muestra mayor flexibilidad en comparación con Portugal e Irlanda en los años del 2000. Parece convincente asociar la rigidez más baja en el país griego con su euroización en 2001, y si bien la protección del empleo en Alemania sigue siendo baja, la brecha entre una y otra nación se ha acortado significativamente en los años 2000.

Por lo demás, no obstante que la protección más baja y la mayor flexibilidad en los mercados laborales de Grecia durante los años 2000 son técnicamente consistentes con un régimen de cambio rígido, es algo que socialmente aborrece la clase trabajadora. Por tanto, ante los recortes en el gasto público en los albores de la crisis de la deuda de 2010, es de esperar que haya tremenda protesta pública entre la población griega.

GráfICA 18

Rigurosidad de la protección del empleo

$(1992=100)$

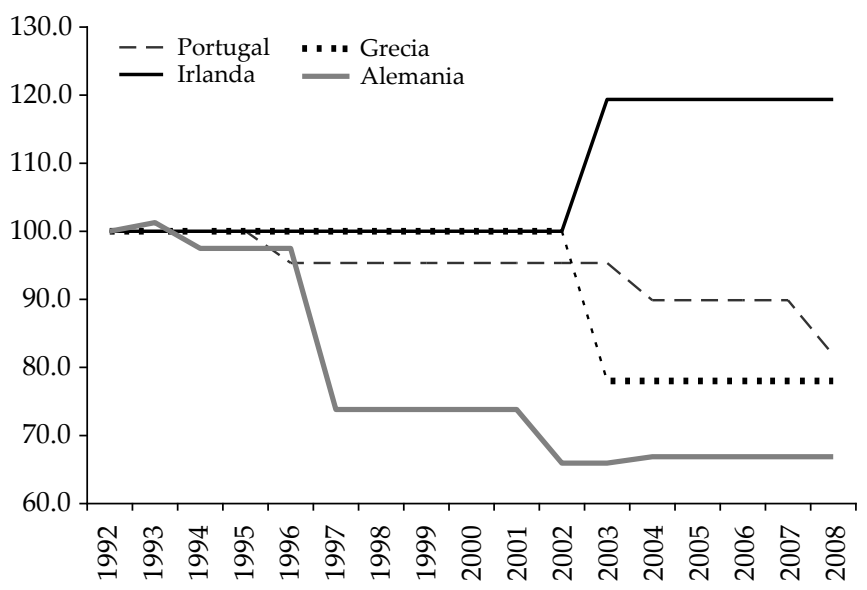

Fuente: cálculo con base en datos de la OCDE. 


\section{Discusión}

Puede que sea muy tarde para que Grecia — un participante "ya arraigado"— renuncie al euro, abandone la Unión y, en consecuencia, restaure el dracma; es seguro que ello instigaría liquidaciones, movimientos especulativos contra esa moneda y fuertes depreciaciones del dinero resurrecto. Finalmente, ello podría llevar a un problema de deuda aún más profundo en la medida que la gran mayoría de lo adeudado está denominado en euros. Aun cuando la devaluación podría ser favorable desde el punto de vista de las exportaciones, la depreciación podría acarrear una pérdida abrupta de poder de compra de un nuevo dracma, crecientes presiones inflacionarias y fuga de capitales.

No obstante lo anterior, países prospectos a ingresar a la Unión como Hungría, Letonia, Lituania, Dinamarca y otros participantes del Mecanismo de Tipos de Cambio II (MTC II), lo mismo que las autoridades de la eurozona central, podrían hacer uso de la experiencia griega y de los aspectos que destaca este trabajo.

Para resumir, en el cuadro 1 aparecen reunidas las principales observaciones discutidas. Las primeras filas destacan los problemas que enfrentó Grecia. Puede que valga la pena mencionar que da la impresión que este país era más competitivo respecto a Alemania antes de la unificación, pero menos después de la misma.

En términos de los criterios de las ZMO, de alguna forma parece ser que Grecia mantiene grados de disminución de intensidad de comercio bilateral e inflación convergente con Alemania, incluso años después de la euroización. La dimensión inflacionaria es la que destaca Robert Mundell (por ejemplo Mundell, 2000) como la más importante para la convergencia monetaria, en tanto que refleja correlación en una multitud de variables económicas en el largo plazo. En cuanto a la simetría del ciclo de tasa de interés, la afinidad con la alemana sólo es marginalmente alta en comparación con la de Estados Unidos. Mientras tanto, también hay indicios de creciente convergencia en flexibilidad del mercado de trabajo con Alemania.

Para resumir, dejando de lado los problemas que destacamos en la sección dos y la pérdida de competitividad señalada en la tercera, Grecia, al igual que Portugal e Irlanda, también mantiene una falta de conformidad con los criterios de las ZMO particularmente en las dimensiones de comercio y convergencia de inflación. Si bien la pérdida de competitividad, ampliación de los déficit comerciales y poca IED pueden estar ligadas con la sobre-apreciación de la 
moneda griega al momento en que se euroizó, hay razones para creer que los problemas de presupuesto están asociados con una falta de conformidad con lo que prescriben las zMO.

En ausencia de tipo de cambio flexible y una política monetaria independiente que pudieran amortiguar los choques generados por las perturbaciones externas, el incremento en la expansión fiscal en Grecia (como lo observaron, por ejemplo, Buiter y Rahbari, 2010, y Matsaganis, 2011) podría deberse a los intentos - deliberados o inadvertidos-de las autoridades por reducir los efectos adversos de los choques producto de la asimetría macroeconómica entre Grecia y Alemania (esto es, debido a la falta de sincronización del ciclo económico y disminución en la apertura comercial con Alemania).

Esta observación complementa lo señalado por Krugman (2012), que postula que las transferencias fiscales (por ejemplo, en la forma de transferencias de asistencia social) de estados con excedente a estados deficitarios hubieran evitado los desequilibrios económicos y, por lo tanto, la crisis de deuda. La insuficiencia de mecanismos de estabilización automática en el gobierno federal orilló al gobierno griego a solicitar préstamos a los estados ricos, principalmente Alemania y Países Bajos, y ésta puede ser una de las razones detrás de la crisis de deuda en Grecia. Por supuesto, el "daño moral", es decir, la creencia de que había un respaldo implícito de las autoridades de la UEM no fue un elemento clave en esta historia.

En efecto, el aumento de las tasas de crecimiento y la rápida reducción de los costos de endeudamiento en Grecia, como lo señalaron Milios y Sotiropoulos (2010), fue lo que impulsó la llegada de flujos de capital especulativo a este país, pero ello no fue más que la manifestación de la ausencia de conformidad en las áreas económicas de las ZMO, como la simetría del ciclo económico e intensidad del comercio bilateral (de haberse incrementado la apertura comercial con Alemania, los precios en ambos países habrían convergido más y ello habría eliminado parte de las utilidades "por encima del promedio" de las inversiones en Grecia).

Uno puede conjeturar que, en presencia de rigidez de precios y salarios - particularmente en el corto plazo- suscribir la política monetaria de Alemania en los años previos a la euroización no fue una medida adecuada para una Grecia que sufría de desempleo relativamente alto (véase la gráfica 6). Como indican las respectivas gráficas (14 y 15), la simetría del ciclo económico y la apertura comercial con Alemania no fueron sustancialmente altas en ese momento. Sin 
embargo, en el mediano y largo plazos, la política monetaria y la inflación esperada, podrían no estar relacionadas con la tasa de desempleo; en el corto plazo podría haber cierto grado de correlación inversa, donde el dinero caro (para vencer la inflación) lleva al empleo escaso. Para compensar esto, el gobierno griego podría haber incrementado precipitadamente el gasto. En consecuencia, creciente endeudamiento mediante creciente emisión de bonos llevó a una burbuja especulativa y entradas de capital especulativo. Al momento de estallar la burbuja, los flujos de fondos se revirtieron, hubo escasez de endeudamiento adicional y de ingresos para cubrir el servicio de la deuda existente; sobrevino la crisis de deuda.

Cuadro 1

Resumen de las observaciones

Mediciones de desempeño general (como porcentaje del PIB)

Resumen

1 Equilibrio presupuestal del gobierno central

2 Endeudamiento público

3 Balanza en cuenta corriente

4 Inversión extranjera directa

5 Flujos netos de capital privado

En competitividad

1 Tipo de cambio nominal

2 Tipo de cambio real deflacionado por el IPC relativo
El déficit de Grecia siempre ha sido mayor que el de Alemania. Grecia muestra una mejora en el periodo previo a la euroización, aunque se deteriora posterior a la misma.

La deuda griega sobrepasó $100 \%$ del PIB, es significativamente mayor que la de Alemania.

En general, el déficit de Grecia incrementó, mientras que en Alemania el excedente aumentó.

Previo a la introducción del euro en 1999, los flujos hacia Grecia son ligeramente mayores que los dirigidos hacia Alemania, posterior a ello, en promedio, la IED en Grecia de alguna forma es mucho menor.

Los flujos de capital privado hacia Grecia se incrementaron significativamente en niveles mayores en comparación con Alemania desde comienzos de los años 2000.

Antes de que Grecia adoptara el euro había sido significativamente más competitiva que Alemania, Portugal e Irlanda.

Previo a su euroización, Grecia había sido más competitiva en comparación con Alemania y Portugal (en 1999-2000). Al igual que Portugal, Grecia fue menos competitiva en comparación con Alemania e Irlanda después de la euroización. 


\section{Cuadro 1, continuación}

3 Tipo de cambio real deflacionado por el costo unitario de trabajo relativo

$\mathrm{Al}$ igual que Portugal, Grecia fue menos competitiva en comparación con Alemania e Irlanda después de la euroización.

Conformidad con los criterios de la zMO

1 Intensidad del comercio bilateral

La apertura comercial de Grecia con Estados Unidos es consistentemente mayor que con Alemania. De hecho, la apertura con Alemania muestra una tendencia al descenso. Lo mismo para Portugal e Irlanda.

2 Sincronía con el ciclo económico

Grecia muestra mayor convergencia con Alemania que con Estados Unidos. Lo mismo para Portugal e Irlanda.

3 Simetría del ciclo de la tasa de interés real

4 Convergencia en inflación

Grecia muestra convergencia ligeramente mayor con Alemania. Portugal e Irlanda muestran una convergencia ligeramente mayor con Estados Unidos.

La convergencia con Alemania y con Estados Unidos se incrementó significativamente; es más paralela con Estados Unidos.

5 Flexibilidad del mercado laboral

En Grecia es menos flexible respecto a Alemania, aunque muestra convergencia hacia el de esta nación. En años recientes, el mercado laboral de Grecia ha sido más flexible en comparación con el de Portugal e Irlanda.

\section{Conclusiones}

Para recapitular, en la sección dos observamos las serias dificultades económicas de Grecia, sobre todo su preocupante situación presupuestal, esto a partir de aplicar algunos de los indicadores macroeconómicos más utilizados. A continuación examinamos la competitividad internacional de Grecia, centrándonos en mediciones de tipos de cambio real y observamos que el euro ha estado sobrevaluado para esa nación, posteriormente exploramos las dimensiones de convergencia real relacionadas con el marco de la ZMO y detectamos que Grecia cumple notablemente menos con los aspectos de intensidad de comercio y convergencia de inflación.

En conclusión, aun cuando es consistentemente lógico que los problemas en Grecia pudieron verse agravados por la falta de competitividad y de conformidad con los criterios de las ZMO, como lo señalamos en este trabajo, la evidencia muestra que ello está muy lejos de ser suficiente para probar que 
existe una relación causal entre las variables. No obstante, y a pesar de estar lejos de ser una metodología infalible, las inferencias que surgen son suficientemente sustantivas desde un punto de vista teórico para impulsar mayor investigación en este tema.

También cabe señalar que otra limitante de este trabajo es que apenas es una de múltiples posturas que se sostienen en la literatura. Los lectores deben estar conscientes de otros factores como: un excesivo déficit en el gasto, deuda total excedente en relación con el PIB del país, un crecimiento económico casi nulo y una pérdida de calificación en la deuda griega (véase, por ejemplo, Abboushi, 2011). Las debilidades anteriores son resultado de una gobernanza deficiente, tanto de la zona euro como de Grecia (Featherstone, 2011). Al mismo tiempo, gobiernos sucesivos en Atenas no han sido capaces de superar los problemas endémicos de baja competitividad, desequilibrios de comercio e inversión, y deficiente administración fiscal. También se adjudica culpa a los conflictos con el BCE y a los medios por difundir temores entre los contribuyentes de la eurozona.

Alemania ganó competitividad porque pudo presionar más fuerte a sus trabajadores, lo que llevó a excedentes de cuenta corriente persistentes que se tradujeron en inversión extranjera directa y préstamos bancarios a su periferia (Lapavitsas et al., 2010).

Las perspectivas anteriores concuerdan en general y complementan la conclusión del presente trabajo. Si bien los flujos de capital especulativo fueron un factor dominante para la crisis de la deuda griega, pudieron ser tan sólo uno de los síntomas de una debilidad fundamental en Grecia. Si uno recuerda la crisis financiera asiática de 1997-1998, la debilidad fundamental de la economía política fue la fuente de los movimientos especulativos contra el bath tailandes y la rupia indonesia.

\section{REFERENCIAS BIBLIOGRÁFICAS}

Abboushi, S., 2011. Analysis and Outlook of the Greek Financial Crisis. Journal of Global Business Management, 7(1), pp. 1-8.

Arestis, P. y Pelagidis, T., 2010. Absurd Austerity Policies in Europe. Challenge, 53(6), pp. 54-61.

Artis, M. y Zhang, W., 2002. Membership of EMU: A fuzzy clustering analysis of alternative criteria. Journal of Economic Integration, 17(1), pp. 54-79. 
Barbosa, J.R. y Alves, R.H., 2011. Divergent Competitiveness in the Eurozone and the Optimum Currency Area Theory [FEP Documentos de trabajo no. 436]. Facultad de Economía, Universidade do Porto, Portugal.

Baxter, M. y Stockman, A., 1989. Business Cycles and the Exchange-rate Regime. Journal of Monetary Economics, 27(1), pp. 377-400.

Bayoumi, T. y Eichengreen, B., 1997. Ever Closer to Heaven? An Optimum-currencyarea Index for European Countries. European Economic Review, 41, pp. 761-70.

Boreiko, D., 2003. EMU and Accession Countries: Fuzzy Cluster Analysis of Membership. International Journal of Finance and Economics, 8, pp. 309-25.

Buiter, W.H. y Rahbari, E., 2010. Greece and the Fiscal Crisis in the Eurozone [CEPR Policy Insight no. 51]. Centre for Economic Policy Research (CEPR), Londres.

De Grauwe, P. y Ji Y., 2012. Self-fulfilling Crises in the Eurozone: An empirical test. Journal of International Money and Finance, 34, pp. 15-36.

International Monetary Fund, 2012. World Economic Outlook [Chapter 3]. Washington, DC: IMF.

Featherstone, K., 2011. The JCMs Annual Lecture: The Greek sovereign debt crisis and EMU. A Failing State in a Skewed Regime. JCMS: Journal of Common Market Studies, 49(2), pp. 193-217.

Fleming, J.M., 1971. On Exchange Rate Unification. Economic Journal, 81, pp. 467-88. Gerlach, S., 1988. World Business Cycles under Fixed and Flexible Exchange Rates. Journal of Money, Credit and Banking, 20, pp. 621-32.

Ingram, J., 1962. Regional Payments Mechanisms: The Case of Puerto Rico. Chapel Hill: University of North Carolina Press.

Kenen, P., 1969. A Theory of Optimum Currency Areas: An eclectic view. En: Mundell, R.A. y Swoboda, A.K. (eds.). Monetary Problems of the International Economy. Chicago: University of Chicago Press.

Krugman, P., 1990. Policy Problems of a Monetary Union. En: De Grauwe, P. y Papademos, L. (eds.). The European Monetary System in the 1990s. Harlow: Longman.

Krugman, P., 2012. Revenge of the Optimum Currency Area. En: Acemoglu, D., Parker, J. y Woodford, M. (eds.). NBER Macroeconomics Annual 2012 [Vol. 27; pp. 439-448]. Cambridge, MA: National Bureau of Economic Research (NBER).

Lapavitsas, C.; Kaltenbrunner, A.; Lindo, D.; Michell, J.; Painceira, J.P.; Pires, E. y Teles, N., 2010. Eurozone Crisis: Beggar thyself and thy neighbour. Journal of Balkan and Near Eastern Studies, 12(4), pp. 321-73.

Matsaganis, M., 2011. The Welfare State and the Crisis: The case of Greece. Journal of European Social Policy, 21(5), pp. 501-12.

McKinnon, R., 1963. Optimum Currency Areas. American Economic Review, 53, pp. 717-25. Milios, J. y Sotiropoulos, D.P., 2010. Crisis of Greece or Crisis of the Euro? A view from the European "periphery". Journal of Balkan and Near Eastern Studies, 12(3), pp. 223-40. 
Mundell, R., 1961. A Theory of Optimum Currency Areas. American Economic Review, 51, pp. 657-64.

Mundell, R., 2000. Currency Areas, Volatility, and Intervention. Journal of Policy Modeling, 22, pp. 281-99.

Nguyen, T., 2007. East Asian Currency Area: A fuzzy clustering analysis of homogeneity [DPRC Working Paper no. 10]. Development and Policies Research Center (DPRC), Vietnam.

Panico, C. y Purificato, F., 2013. The Debt Crisis and the European Central Bank's Role of Lender of Last Resort. [en línea] Political Economy Research Institute, University of Massachusetts Amherst. Disponible en: <http://www.peri.umass. edu/fileadmin/pdf/working_papers/working_papers_301-350/WP306.pdf > .

Papadimitriou, D.B., Nikiforos, M. y Zezza, G., 2013. The Greek Economic Crisis and the Experience of Austerity: A Strategic Analysis. Annandale-on-Hudson, Nueva York: Levy Economics Institute of Board College.

Quah, C.H., 2012a. Is East Asia as Prepared as Eurozone for Monetary Union? Journal of Business, Economics, and Management, 13(3), pp. 471-88.

Quah, C.H., 2012b. Can Japan or China Replace the US as the Monetary Anchor for Hong Kong and Macau? Asia Pacific Business Review, 18(3), pp. 335-54.

Quah, C.H., 2013a. Clustering Eurozone Cycles. Quality \& Quantity. International Journal of Methodology, pp. 1-16. [en línea] Disponible en: < http://link.springer.com/article/10.1007/s11135-013-9966-6/fulltext.html $>$

Quah, C.H., 2013b. Potential Currency Areas in East Asia using United States, Japan, or China as the Monetary Anchor. Economia Mexicana, Nueva Época, 3(I), pp. 247-79.

Quah, C.H., 2014. Revisiting Business Cycles In Eurozone. Acta Oeconomica (de próxima aparición).

Quah, C.H. y Crowley, P.M., 2010. Monetary Integration in East Asia: A hierarchical clustering approach. International Finance, 13(2), pp. 283-309.

Quah, C.H. y Crowley, P.M., 2012a. Which Country should be the Monetary Anchor for East Asia: The US, Japan or China? Journal of the Asia Pacific Economy, 17(1), pp. 94-112.

Quah, C.H. y Crowley, P.M., 2012b. China and the Dollar: An optimum currency area view. Prague Economic Papers, 4, pp. 391-411.

Quah, C.H. e Ismail, N., 2012. Monetary Integration in East Asia: A critical review. Actual Problems of Economics, 4, abril.

Reinhart, C.M. y Rogoff, K.S., 2008. This Time is Different: A Panoramic View of Eight Centuries of Financial Crises [NBER working papers no. 13882]. NBER, Cambridge, MA. 